\title{
The Effects of Chronic Ingestion of Mercuric Chloride on Fertility and Testosterone Levels in Male Sprague Dawley Rats
}

\author{
John C. Heath, ${ }^{1}$ Y. Abdelmageed, ${ }^{1}$ Tim D. Braden, ${ }^{2}$ and Hari O. Goyal' ${ }^{1}$ \\ ${ }^{1}$ Department Biomedical Sciences, College of Veterinary Medicine, Nursing and Allied Health, Tuskegee University, \\ Tuskegee, AL 36088, USA \\ ${ }^{2}$ Department of Anatomy, Physiology and Pharmacology, College of Veterinary Medicine, Auburn University, Auburn, AL 36049, USA
}

Correspondence should be addressed to John C. Heath, jheath@mytu.tuskegee.edu

Received 21 March 2012; Accepted 6 May 2012

Academic Editor: João B. T. Rocha

Copyright () 2012 John C. Heath et al. This is an open access article distributed under the Creative Commons Attribution License, which permits unrestricted use, distribution, and reproduction in any medium, provided the original work is properly cited.

\begin{abstract}
Although male infertility is well researched, the effects of inorganic mercury on male reproduction and fertility are less well known. Studies pertaining to mercury and male fertility identified reduced concentration of testosterone in the serum of male workers, a toxic influence on fertility of organic mercury compounds within concentrations at the workplace, and increased days to pregnancy. We evaluated the effect of chronic mercuric chloride $\left(\mathrm{HgCl}_{2}\right)$ exposure in male rats on reproductive endpoints. Thirty-day old male Sprague Dawley rats $(n=31)$ were exposed to $0.0,1.0$, or $2.0 \mathrm{mg} / \mathrm{kg} / \mathrm{day}$ of $\mathrm{HgCl}_{2}$ via gavage. After 60 days exposure, they were housed with nonexposed females for 21 days. A survivor analysis revealed the exposed animals took longer to impregnate the females and had a lower rate of impregnation. Further statistical analysis revealed a lower correlation between testicular testosterone levels and days to impregnate, and also lower sperm counts in the epididymis head and body of the exposed males. The results indicate that $\mathrm{HgCl}_{2}$ exposure had significant adverse effects on male rat reproduction endpoints including fertility at a dose that was not clinically toxic.
\end{abstract}

\section{Introduction}

Although male infertility is well documented as a result of exposure to numerous toxicants, the effects of inorganic mercury on male reproduction and fertility are less well known. A 2008 study on the outcome of various heavy metals in relation to semen quality reported data on human nonoccupational exposure to mercury $(\mathrm{Hg})$, and its reproductive outcomes are very sparse [1]. An earlier review of the consequences of mercury exposure in the workplace on fertility and related reproductive outcomes found only three studies pertaining to male fertility [2], which were ambiguous at best. Two studies found effects by establishing the toxic influence on fertility of organic mercury compounds within concentrations that can be seen at the workplace [3] and reduced concentration of testosterone in the serum of male workers, considered to be associated with exposure to inorganic mercury [4]. The third study, looking directly at mercury exposure, found no effects on male fertility; however, the authors relied on the memory of both workers and spouses to obtain data [5]. An additional study found no effects on fertility when workers chronically exposed to mercury vapor were assessed by questionnaire [3].

Studies in Hong Kong reported more than one-third of male partners of infertile couples had elevated blood mercury concentrations. Although the results were not statistically significant, a trend towards a decline in all aspects of semen quality when the blood mercury concentration was elevated was reported $[6,7]$. Similarly, workers exposed to $\mathrm{Hg}$ vapor, which frequently exceeded the maximum allowable concentration, had hypospermia and a considerable increase in the number of abnormal sperm in the ejaculate [8].

An in vivo study using adult male mice found a reduction in sperm count in the testis, vas deferens, and cauda epididymis revealing the inhibitory effects of mercuric chloride $\left(\mathrm{HgCl}_{2}\right)$, on spermatogenesis [9]. Rats exposed to $\mathrm{HgCl}_{2}$ for 81 days experienced a reduction in the weights of the left and right testes and prostate in a high-dose group, and the seminal vesicles weights, in mid and high-dose groups, were significantly decreased when compared to controls [10]. 
Male fertility can be impaired by various toxicants known to target Sertoli cells, which play an essential role in spermatogenesis. Sertoli cells from male Sprague-Dawley rats exposed in vitro to mercury had severely inhibited inhibin production [11]. Bull spermatozoa exposed to 50$300 \mu \mathrm{mol} / \mathrm{L}$ concentration range of $\mathrm{HgCl}_{2}$ revealed reduced sperm membrane and DNA integrity [12]. A lipoperoxidation test performed on sperm membranes from normospermic individuals showed mercury in different concentrations and induced a significant peroxidation to the human sperm membranes in a concentration-dependent manner. Excessive amounts of mercury in the seminal plasma appear to be related to abnormal spermatozoal function [13]. Furthermore, epididymal spermatozoa obtained from adult rats and incubated with $\mathrm{HgCl}_{2}$ for 3 hours showed markedly reduced motility, plus other characteristics, that point to oxidative stress by the $\mathrm{HgCl}_{2}$ in a dose-dependent manner [14].

The above-cited research demonstrates that in human studies there is some evidence inorganic mercury has an effect on male fertility. This is supported by both in vivo and in vitro studies, which indicate strong evidence that $\mathrm{HgCl}_{2}$ has an effect on the development of sperm together with the integrity of the sperm after spermogenisis [9-14]. However, what form the effect on fertility due to inorganic mercury has on males has not been adequately reported. The study described here reports the effects on fertility of exposure to mercuric chloride in male Sprague Dawley in terms of both the reduced probability of the male to impregnate a female in a dose-dependent fashion, plasma and testicular testosterone levels, and the correlation between the two.

\section{Method}

2.1. Subjects. Thirty-one male Sprague Dawley rats, 22 days of age, were purchased from Harlan Sprague-Dawley (Indianapolis, IN). Each subject was randomly assigned to one of three experimental groups, control, low $\mathrm{HgCl}_{2}$, and high $\mathrm{HgCl}_{2}$. They were housed in polycarbonate cages (two per cage) on beta chip bedding (Northeastern Products, Warrensburg, NY) with cage mates belonging to the same experimental group. Subjects were given access to Purina certified rodent chow 5001 (Purina Mills, St. Louis, MO) and water ad libitum. Room conditions were controlled at $22^{\circ}-23^{\circ} \mathrm{C}$ ambient temperature, $50 \%-60 \%$ relative humidity, and 12 hour light/dark cycle. All conditions conformed to the regulations of, and were approved by, the Tuskegee University Animal Care and Use Committee.

2.2. Preparation of $\mathrm{HgCl}_{2}$ Solutions. A concentration of $1.0 \mathrm{mg} / \mathrm{mL}$ was prepared using 1 gram of mercuric chloride $\left(\mathrm{HgCl}_{2}\right.$; SIGMA-Aldrich Inc, St. Louis, MO) added to a solution of $998.5 \mathrm{~mL}$ of de-ionized $\mathrm{H}_{2} \mathrm{O}$ and $1.5 \mathrm{~mL}$ of nitric acid $\mathrm{HNO}_{3}$ (to aid dilution). Similarly, a concentration of $0.5 \mathrm{mg} / \mathrm{mL}$ solution was prepared with $0.5 \mathrm{mg}$ of $\mathrm{HgCl}_{2}$. added to a solution of $998.5 \mathrm{~mL}$ of de-ionized $\mathrm{H}_{2} \mathrm{O}$ and $1.5 \mathrm{~mL}$ of nitric acid $\mathrm{HNO}_{3}$.

2.3. Administration of $\mathrm{HgCl}_{2}$. At age 30 days, subjects in the $\mathrm{HgCl}_{2}$ groups began exposure to the solutions of mercuric chloride $\left(\mathrm{HgCl}_{2}\right)$ in concentrations of $1.0 \mathrm{mg} / \mathrm{kg} /$ day (low $\mathrm{Hg}$ ) or $2.0 \mathrm{mg} / \mathrm{kg} /$ day (high $\mathrm{Hg}$ ) via gavage. Solution administered each day ranged from 0.48 to $7.2 \mathrm{~mL}$ dependent on the weight of the animal and the exposure concentration. Controls were given an equivalent amount of de-ionized water (with no nitric acid added) using the same administration method. The amount of $\mathrm{HgCl}_{2}$ administered each day, to each subject, was calculated based upon its weight and exposure group. Each subject was weighed three times per week and the dose was adjusted accordingly. The solution was administered seven days a week via gavage until the subjects reached 90 days of age thus, total exposure was for 60 days. Concentration of exposure to $\mathrm{HgCl}_{2}$, route of administration, and exposure period were selected to mimic exposure paradigms used in previous published studies from our lab $[10,15]$. In Atkinson et al. [10], the maximum tolerated dose (MTD) was obtained from prior studies [16, 17] and the National Toxicology Program Technical report [18]. Based on these data concentrations of $1.0 \mathrm{mg} / \mathrm{kg} /$ day and $2.0 \mathrm{mg} / \mathrm{kg} /$ day were used in our study on female rats [15], the higher dose being the highest dose we found that did not show a manifestation of physical signs of mercuric chloride exposure. The exposure paradigm used in this study allows us to do a direct comparison to the effects of exposure in female rats.

2.4. Breeding Females. Thirty-one female Sprague Dawley rats aged 80 days were purchased from the same supplier as the males. The females were acclimated for 10 days and then housed in the same conditions as the males, two to a cage, and fed the same diet. None of the females were purposefully exposed to $\mathrm{HgCl}_{2}$. No analysis of the females, other than period from cohabitation to fertilization, was performed, and all females were euthanized at the completion of the study.

2.5. Breeding Protocol. At 90 days of age, exposure to $\mathrm{HgCl}_{2}$ ceased and each male was housed with an unexposed female for 21 days. All females were at the same stage of the estrous cycle at the beginning of their cohabitation with males. After 21 days, the breeding pairs were separated and the males were euthanized using $\mathrm{CO}_{2}$ inhalation after which necropsies were performed. The females were observed for a further 21 days and all pregnant females were allowed to come to term.

2.6. Plasma and Testicular Testosterone. For plasma testosterone, one blood sample was collected by cardiac puncture from each animal just prior to necropsy. For intratesticular testosterone, a part of the right testis was collected from each animal at the time of necropsy. Both plasma and testicular parenchyma were frozen at $-20^{\circ} \mathrm{C}$ until assayed. Testes were processed in accordance with the protocol described by Park et al. [19]. Briefly, 10-30 mg of testicular tissue was homogenized in phosphate-buffered saline (PBS; $0.01 \mathrm{M}$ phosphate, $\mathrm{pH} 7.4$ ). Eight volumes of ether were added to the homogenate and vortexed vigorously. The aqueous phase was snap-frozen, and the organic supernatant was transferred to a secondary tube and air-dried. Just prior to assay, samples were resuspended in phosphate-buffered saline. Testosterone 
TABLE 1: Mean weights of subjects across exposure period.

\begin{tabular}{|c|c|c|c|c|c|c|c|c|c|c|c|c|c|c|c|c|c|c|c|c|}
\hline \multicolumn{21}{|c|}{ Days of $\mathrm{HgCl}_{2}$ exposure } \\
\hline & \multicolumn{2}{|l|}{1} & \multicolumn{2}{|c|}{6} & \multicolumn{2}{|c|}{13} & \multicolumn{2}{|c|}{20} & \multicolumn{2}{|c|}{27} & \multicolumn{2}{|c|}{34} & \multicolumn{2}{|c|}{41} & \multicolumn{2}{|c|}{48} & \multicolumn{2}{|c|}{55} & \multicolumn{2}{|c|}{59} \\
\hline Exposure & Mean & SE & Mean & SE & Mean & SE & Mean & SE & Mean & SE & Mean & SE & Mean & SE & Mean & SE & Mean & SE & Mean & SE \\
\hline $0.0 \mathrm{HgCl}_{2}$ & 85 & 2.0 & 144 & 3.3 & 194 & 4.4 & 240 & 4.6 & 280 & 5.3 & 315 & 5.7 & 341 & 6.8 & 366 & 7.4 & 369 & 6.8 & 364 & 4.9 \\
\hline $1.0 \mathrm{HgCl}_{2}$ & 82 & 2.3 & 140 & 3.5 & 187 & 4.2 & $231^{\#}$ & 4.1 & $266^{\#}$ & 4.1 & $296^{\#}$ & 5.8 & $319^{\#}$ & 5.4 & $340^{\# *}$ & 5.7 & $341^{\# *}$ & 5.4 & $349^{\#}$ & 5.4 \\
\hline $2.0 \mathrm{HgCl}_{2}$ & 79 & 3.3 & 131 & 3.8 & $174^{*}$ & 5.0 & $212^{*}$ & 5.1 & $241^{*}$ & 6.4 & $271^{*}$ & 8.0 & $281^{*}$ & 7.7 & $307^{*}$ & 8.0 & $310^{*}$ & 8.3 & $319^{*}$ & 7.9 \\
\hline
\end{tabular}

Mean columns: mean weight in grams for an exposure group on a particular day of exposure. SE: standard error of the mean. ${ }^{*}$ : significant difference from controls. ${ }^{\#}$ : significant difference from $2.0 \mathrm{mg} / \mathrm{kg} \mathrm{HgCl} 2$ group. Post hoc test using fisher LSD test. $P<0.05$.

in plasma and testicular tissue was measured using a COATA-COUNT testosterone radioimmunoassay (Diagnostic Products Corporation, Los Angeles, CA) according to manufacturer's protocol. The sensitivity of the assay was $0.2 \mathrm{ng} / \mathrm{mL}$. The intra-assay and interassay coefficients of variations were $6 \%$ and $12 \%$, respectively.

2.7. Preparation of Samples. The testes were homogenized in $50 \mathrm{~mL}$ PBS for 30 seconds, filtered, and $1.5 \mathrm{~mL}$ was placed in a separate container. The same process was performed on the epididymis head and body, as well as the epididymis tail.

2.8. Analysis of Samples. Samples were prepared for sperm count by mixing $100 \mu \mathrm{L}$ of filtered homogenate with $100 \mu \mathrm{L}$ of trypan blue and $50 \mu \mathrm{L}$ of saline. The sample substance was kept overnight for better result. Eight to ten $\mu \mathrm{L}$ of the mixture was spread on a hemocytometer and the sperm count was conducted under a light microscope. Two samples of each were prepared and counted to ensure accurate data.

2.9. Data Analysis. Data on when the females were impregnated is incorporated in Stratified Kaplan-Meier estimates followed by log-rank tests, which were conducted to determine the probability of an exposed male impregnating a female. The independent variable was the period of time that the $\mathrm{HgCl}_{2}$-exposed male cohabited with the female before she became pregnant. The day of impregnation was calculated by subtracting the length of pregnancy ( 22 days) from the total period from the beginning of cohabitation until birth of the offspring. Subjects were right censored if no birth occurred. Right censoring is required in survival analysis to indicate the subject was not in the experiment long enough to experience the measured variable, that is, the male did not impregnate the female.

Body weight was analyzed using repeated measures ANOVA $3\left(\mathrm{HgCl}_{2}\right) \times 8$ (length of exposure) factorial design, with duration of exposure as the repeated measure. The first weight taken and every subsequent fourth weight taken were used as the repeated measure. Other variables were analyzed using one-way ANOVA $3\left(\mathrm{HgCl}_{2}\right) \times$ quantity or number of measured variable. When a significant difference was observed, a post hoc analysis, as described below, was performed to identify the differences between the groups. All results were considered significant at $\alpha=0.05$. A Pearson product-moment correlation analysis with a Bonferroni correction for probability was performed between latency to impregnate the female by the male and testicular testosterone level.

\section{Results}

3.1. Body Weight. A repeated measures ANOVA revealed both a main effect of $\mathrm{HgCl}_{2}\left(\mathrm{~F}_{(2,28)}=14.07, P<0.001\right)$ and an interaction between $\mathrm{HgCl}_{2}$ concentration and exposure duration $\left(\mathrm{F}_{(16,252)}=14.07, P<0.001\right)$. There was also a significant difference in weight at necropsy between the exposure groups $\left(\mathrm{F}_{(2,27)}=7.193, P=0.003\right)$. Post hoc analysis using a Bonferroni correction revealed a significantly lower weight for the high $\mathrm{Hg}$ compared to controls $(P=0.003)$, and the low $\mathrm{Hg}(P=0.045)$, but not between the controls and the low $\mathrm{Hg}(P=0.525)$, see Figure 1 . Table 1 shows the weights and significant difference in weights during the progression of exposure. The high $\mathrm{Hg}$ group was significantly different from the control group after 13 days exposure but remained statistically equal to the low $\mathrm{Hg}$ exposure group until 20 days of exposure.

3.2. Latency to Impregnation. Within the three exposure groups $100 \%$ (10/10), unexposed females from the control $\mathrm{HgCl}_{2}$ group gave live birth. In the low $\mathrm{Hg}$ and high $\mathrm{Hg}$ groups, $10 / 11$ and $7 / 10$ unexposed females, respectively, gave live birth. Figure 2 displays the Kaplan-Meier survival curves showing the probability of a male impregnating an unexposed female. Subjects were right censored if they failed to impregnate within 21 days of mating. The control group impregnated the females within 13 days of mating, (mean days to impregnation 5.9). The low Hg group had an impregnation rate of $91 \%(10 / 11)$ with one animal failing to impregnate (mean days to impregnation 7.5). The high $\mathrm{Hg}$ group had an impregnation rate of $70 \%(7 / 10)$, with a mean period to impregnate of 12.5 days. A log-rank test revealed the high $\mathrm{Hg}$ group had a significantly greater probability of not impregnating a female $\left(\chi_{(1,19)}^{2}=5.29, P=0.021\right)$ than the control group.

\subsection{Testosterone Levels}

3.3.1. Testicular Testosterone. A one-way ANOVA $3\left(\mathrm{HgCl}_{2}\right)$ $\times$ testicular testosterone levels per gram of testes tissue revealed a significant difference $\left(\mathrm{F}_{(2,26)}=5.684, P=0.009\right)$. Post hoc analysis using the Tukey honest significance test (Tukey's HSD test) revealed that both exposure groups had significantly lower levels of testicular testosterone than 


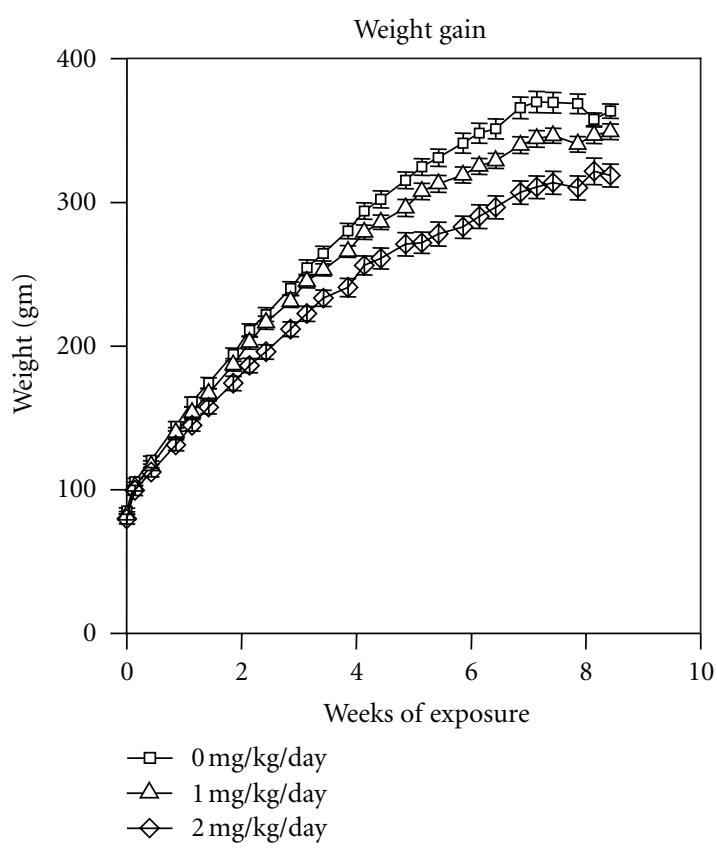

(a)

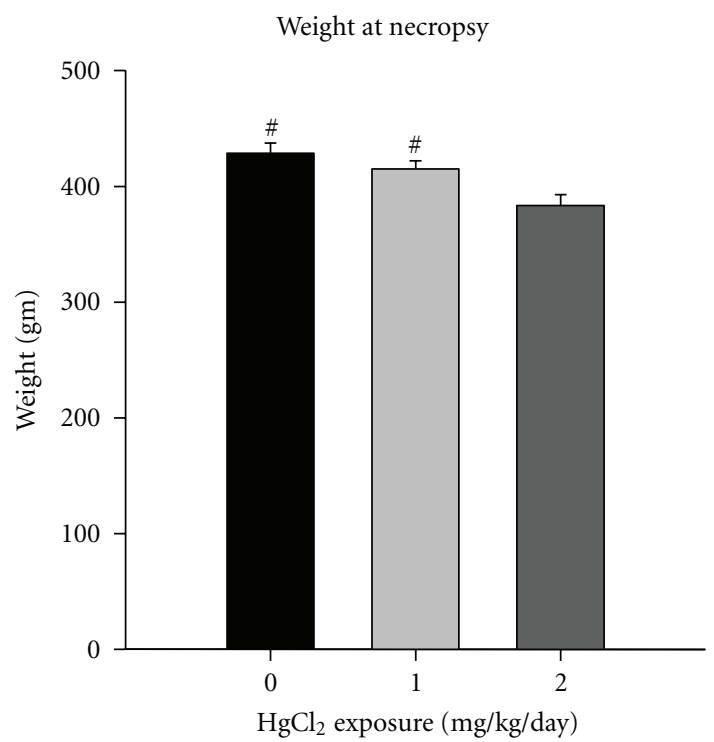

(b)

FIGURE 1: Body weight gain (a) and weight at necropsy (b) of male rats exposed to $0,1.0$, or $2.0 \mathrm{mg} / \mathrm{kg} /$ day of $\mathrm{HgCl}_{2}$ by gavage for 60 days and housed with unexposed female rats for 21 days. Data are mean and standard error. (b) Weight at necropsy. ${ }^{\# A}$ significant difference from the $\mathrm{HgCl}_{2}$ group $2.0 \mathrm{mg} / \mathrm{kg}(P<0.05)$.

controls (low Hg, $P=0.016$, high $\mathrm{Hg}, P=0.023$ ); however, the exposure groups did not differ from each other. Figure 3 shows the levels of testicular testosterone (a) and the distribution across exposure levels (b). While the controls show higher levels of testicular testosterone, both $\mathrm{Hg}$ groups are similar except $30 \%$ of the subjects in the high group had lower testicular testosterone levels than subjects in the low Hg group.

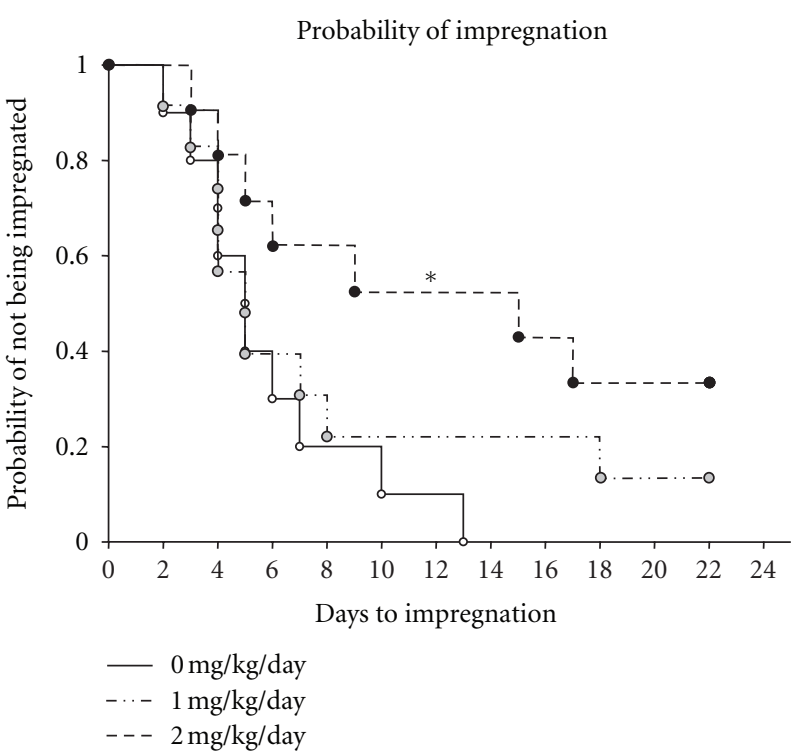

Figure 2: Kaplan-Meier survival curves. Probability of an exposed male impregnating an unexposed female. ${ }^{*}$ Indicates a significant difference from the control group. $P<0.05$.

3.3.2. Plasma Testosterone. A one-way ANOVA conducted on plasma testosterone levels across exposure groups revealed no significant difference in levels at $\alpha=.05$; however, $P$ values were approaching significance $\left(\mathrm{F}_{(2,26)}=3.102, P=\right.$ 0.062). A post hoc test using the least square difference (LSD) method showed that the low $\mathrm{Hg}$ group had a significantly lower level of plasma testosterone than controls. However, it should be noted the LSD method is a somewhat less conservative test of analysis. Inspection of the distribution of plasma testosterone (see Figure 4) shows a marked higher level of testosterone in the control group, with both exposure groups in a similar lower range. Distribution of plasma testosterone across the $\mathrm{Hg}$ groups is very similar to the distribution of testicular testosterone.

3.4. Correlation of Testosterone and Latency to Impregnate. Pearson correlation coefficients, with Bonferroni corrected $P$ values, were calculated between both testicular and plasma testosterone levels and days required to impregnate an unexposed female. For controls, testicular testosterone levels were inversely correlated to latency to impregnate $(r=$ $-0.80, P=0.012)$ indicating that as testicular testosterone levels decreased the days taken to impregnate increased. However, for the low $\mathrm{Hg}$ group the Pearson coefficients were considerable lower, positive, and not significant $(r=.47, P=$ 0.411), while for the high $\mathrm{Hg}$ group, there was no correlation $(r=.07, P=1.0)$, (Figure 5). A similar pattern was observed for plasma testosterone levels except the correlation coefficients were lower than for testicular testosterone, and none of the correlations were significant when using the Bonferroni correction, controls $(r=-.48, P=0.32)$, low $\mathrm{Hg}(r=$ $0.29, P=0.89)$, high $\mathrm{Hg}(r=.08, P=1.0)$. A further Pearson coefficient was calculated on the results of the testicular testosterone and plasma testosterone against latency to 


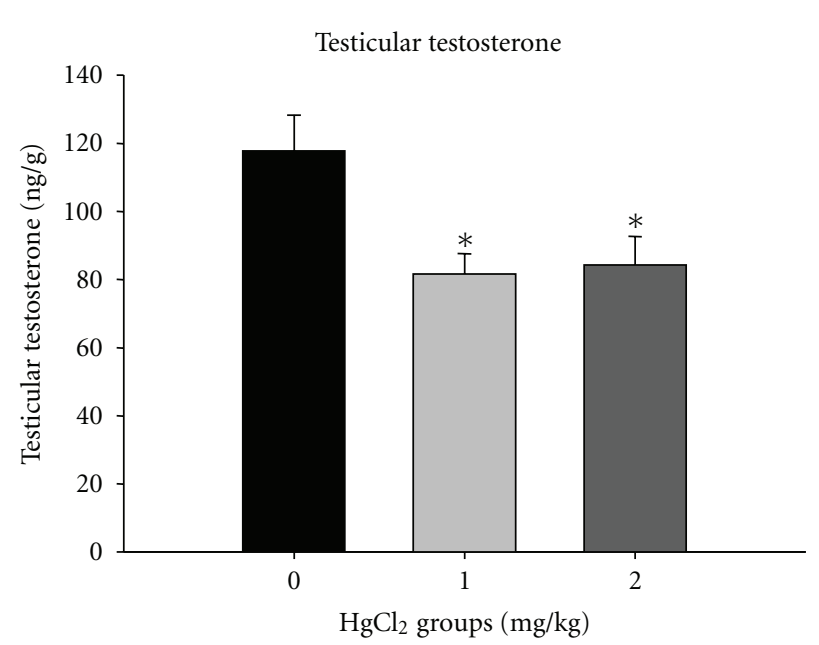

(a)

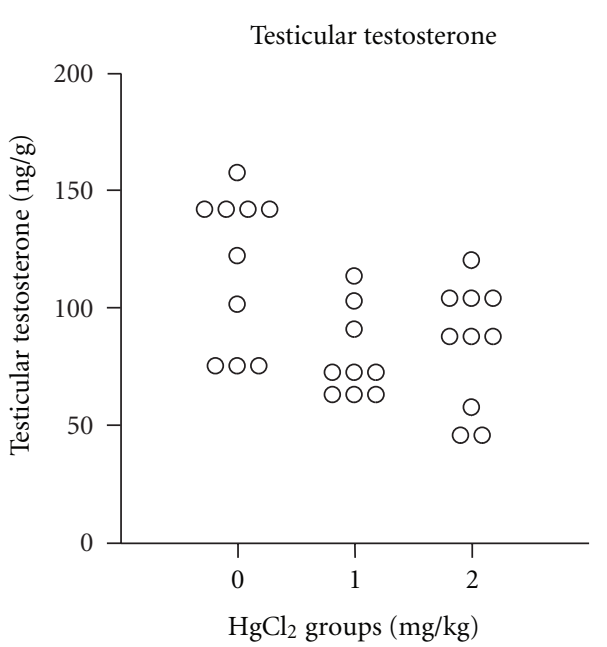

(b)

FIgURE 3: Testicular testosterone levels (a) levels of testes testosterone (ng/gm) for each exposure group. (b) Distribution of testes testosterone for each exposure group. Data are mean and SE. ${ }^{*}$ Represents a significant difference from controls. $P<0.05$.

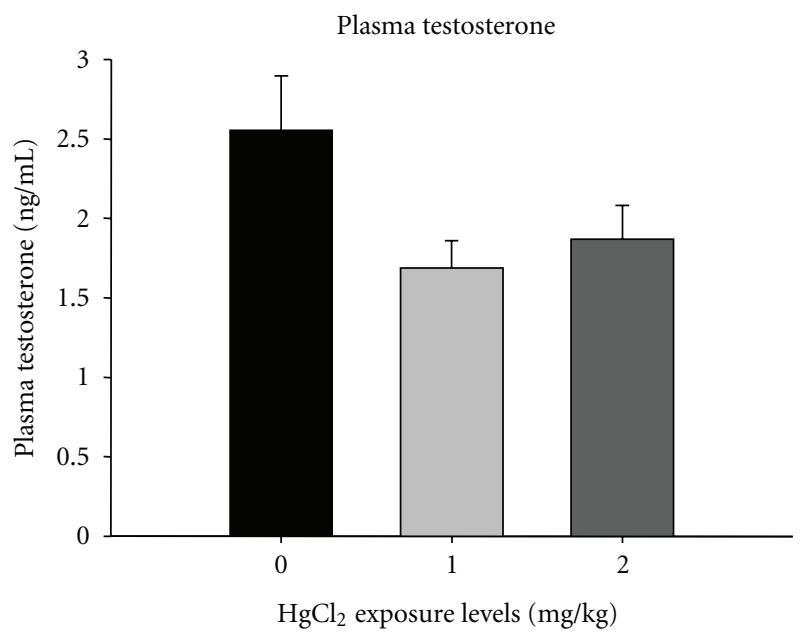

(a)

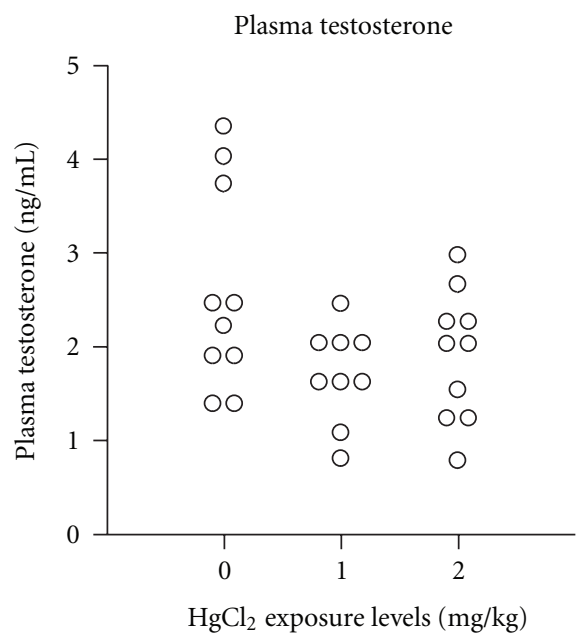

(b)

Figure 4: Plasma testosterone levels (a) levels of blood plasma testosterone (ng/g) for each exposure group. (b) Distribution of blood plasma testosterone for each exposure group. Data are mean and SE. No significant difference was found between groups.

impregnate. Results showed a high correlation $(r=0.9996$, $P=0.17)$ between these results.

3.5. Sperm Count of Epididymus Head and Body. A one-way ANOVA conducted across the sperm count of the epididymis head and body for the three $\mathrm{HgCl}_{2}$ concentrations showed a significant reduction in the sperm count $\left(\mathrm{F}_{(2,27)}=4.428\right.$, $P=0.022$ ) (Figure 6). Post hoc analysis revealed that both the low $(P=0.048)$ and the high $(P=0.008) \mathrm{HgCl}_{2}$ groups had significantly lower sperm counts than the controls.

\section{Discussion}

The present study was designed to address the effects on fertility of mercuric chloride $\left(\mathrm{HgCl}_{2}\right)$ toxicity in growing male rats. There were five main findings. There was an increased latency of the exposed males to impregnate the females as exposure concentrations increased. A decrease in the number of females impregnated was observed as $\mathrm{HgCl}_{2}$ exposure concentrations increased. Both testicular and plasma levels of testosterone decreased in the exposed animals. Correlation between testicular testosterone levels and the latency to impregnate a female decreased and lost its significance as $\mathrm{HgCl}_{2}$ exposure concentrations increased. Sperm count in the epididymis head and body showed a significant decrease with exposure to $\mathrm{HgCl}_{2}$.

Previous studies have reported the effects of mercury ( $\mathrm{Hg})$ toxicity on fertility in the male human populations [25] and in various animal populations [9-12]; however, for inorganic mercury although the underlying mechanisms are relatively well understood, how inorganic mercury toxicity in male fertility manifests itself has remained relatively obscure. 
Correlations of testosterone and latency to impregnate
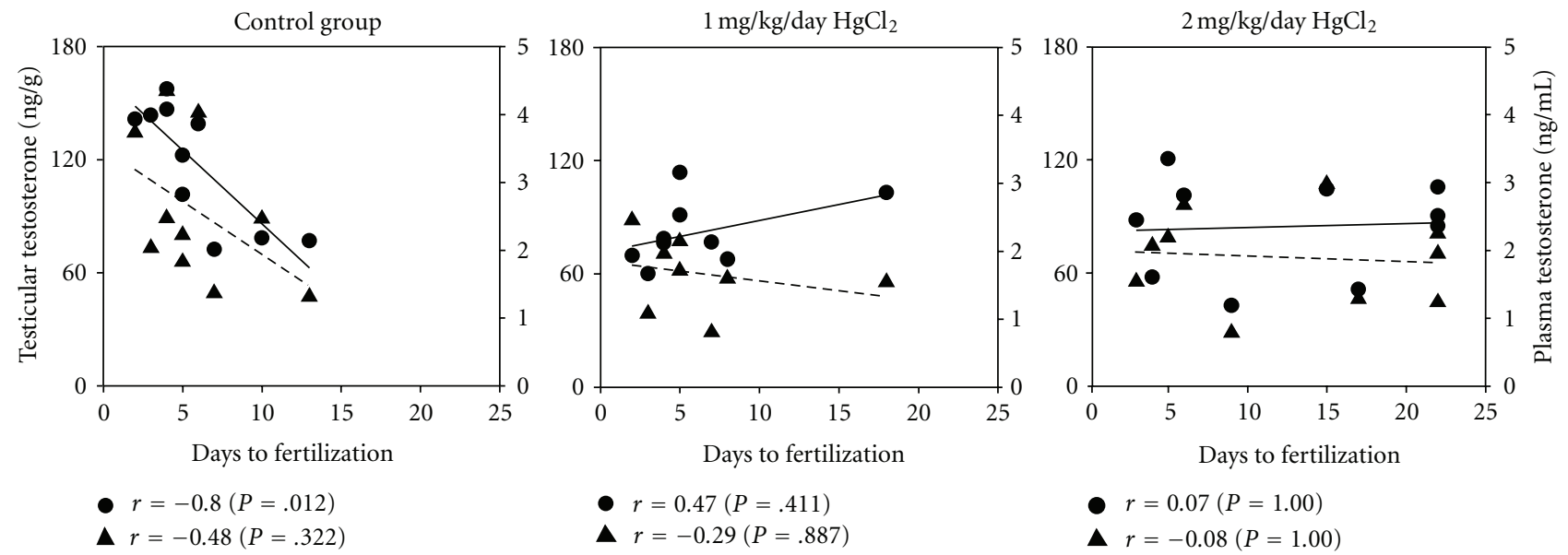

FiguRE 5: Correlation of testicular testosterone levels and plasma testosterone levels to days required to impregnate an unexposed female. (a) controls, (b) $1.0 \mathrm{mg} / \mathrm{kg} /$ day $\mathrm{HgCl}_{2}$, (c) $2.0 \mathrm{mg} / \mathrm{kg} /$ day $\mathrm{HgCl}_{2}$. • Indicates testicular testosterone levels; $\boldsymbol{\Delta}$ indicates plasma testosterone levels.

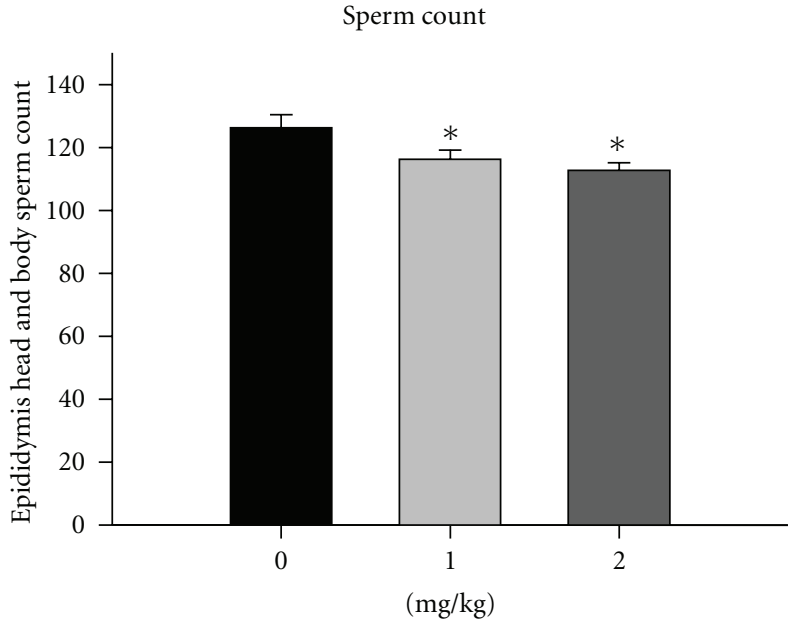

(a)

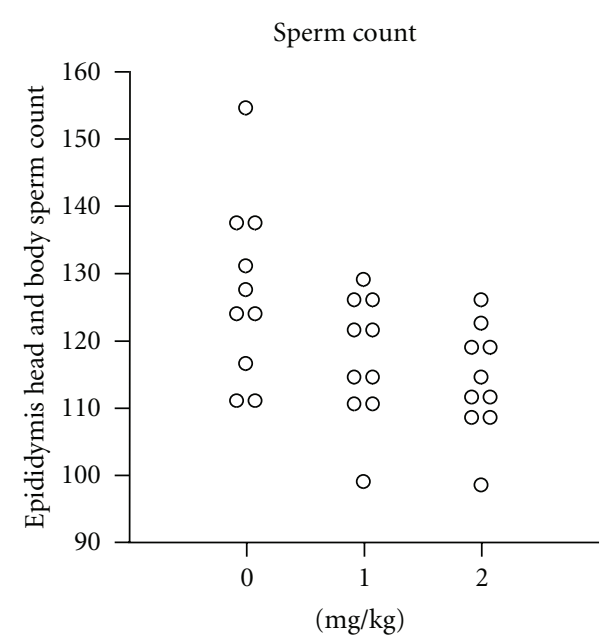

(b)

FIGURE 6: (a) Sperm count of the epididymis head and body at necropsy for each $\mathrm{HgCl}_{2}$ exposure group. (b) Distribution of the epididymis head and body sperm count at necropsy for each exposure group. Data are mean and SE, *: a significant difference from the control group $(P<0.05)$. Scale on " $y$-axis" differs for each chart to give better representation of data.

The concentrations of mercuric chloride used in this study were selected to mirror the doses that we reported in a similar study using female rats [15] thus giving us the opportunity to show a direct comparison in effects across the sexes. As in the case of the females, no adverse physical signs of $\mathrm{Hg}$ toxicity were observed nevertheless, there was a decrease in weight gain in the exposed groups and significantly lower body weights for the high $\mathrm{HgCl}_{2}$ group compared to controls at necropsy (see Table 1 and Figures 1(a) and 1(b)). This was in contrast to the females in which both exposure groups had significantly lower weight gains from controls [15]. Even though no overt physical signs were observed, the exposure concentrations used in this study cannot be construed as a safe level of intoxication, and cannot be extrapolated to a human population. A previous study reported that internal damage from mercury exposure can cause increased cardiovascular risk. Chronic exposure to low concentrations of mercury ( 1 dose $4.6 \mu \mathrm{g} / \mathrm{kg}$, subsequent doses of $0.07 \mu \mathrm{g} / \mathrm{kg} /$ day for 30 days) in Wistar rats promotes endothelial dysfunction as a result of the decreased nitric oxide bioavailability induced by increases in oxidative stress [20]. However, they do tend to support, in rats, a concentration of $\mathrm{HgCl}_{2}$ that does not convey any outward physical signs of toxicity, other than weight change, when administered as described in this experiment. This does not mean, however, that internal damage did not occur due to $\mathrm{HgCl}_{2}$ toxicity.

\subsection{Increased Latency of the Exposed Males to Impregnate} the Females. Our results showed a significant increase in the length of time needed for exposed males to impregnate 
unexposed females. Concurrently, as the exposure concentration increased, a decrease was observed in the number of females that were impregnated. These data support the findings that a lower mating index was found in a dose-response fashion in males rats exposed to $\mathrm{HgCl}_{2}$ in their drinking water [21] as well as a lower fertility index for males [10].

4.2. Changes in Levels of Testosterone. While testicular testosterone levels were significantly different from each other, plasma testosterone levels were not. However, the distributions for both measures were remarkably similar and plasma testosterone levels were approaching significance (see Figures 3(a), 3(b), 4(a), 4(b)). One of the few measures that have been reported as an effect on the male fertility in human populations is a reduction in circulating testosterone levels. In male workers exposed to inorganic mercury and showing a mean blood mercury level of $46 \mathrm{nmol} / \mathrm{L}$, a statistically significant positive correlation between total testosterone and the cumulative mercury dose index was observed even when other factors such as age and smoking were taken into account [4]. However, in a study on subfertile men in Hong Kong no statistical difference in circulating testosterone levels were found for subjects with $50 \mathrm{nmol} / \mathrm{L}(\sim 10 \mu \mathrm{g} / \mathrm{L})$ or higher blood $\mathrm{Hg}$ levels, though the authors attribute the lack of statistical significance to a small sample size, [7]. In a recent study, rats exposed orally to concentrations of 50 and $100 \mathrm{ppm} \mathrm{HgCl}_{2}$ for 90 days recorded almost identical serum testosterone levels as our animals at 2.02, 1.72 , and $1.62 \mathrm{ng} / \mathrm{mL}$ for controls, 50 and $100 \mathrm{ppm} \mathrm{HgCl}_{2}$, respectively [21]. Similar results were seen in two other studies that exposed adult male albino mice to $1.25 \mathrm{mg} / \mathrm{kg}$ of $\mathrm{HgCl}_{2}$ daily for 30 days [9] or 45 days [22] by gavage. In the first study, serum testosterone from controls was recorded at $4.50 \mathrm{ng} / \mathrm{mL}$, while exposed animals had a level of $2.6 \mathrm{ng} / \mathrm{mL}$. After a withdrawal from the $\mathrm{HgCl}_{2}$ for 45 days, serum testosterone had recovered to $4.1 \mathrm{ng} / \mathrm{mL}$ [9]. In the second study, serum testosterone levels in controls were very similar $(4.21 \mathrm{ng} / \mathrm{mL})$, while the exposed animals showed a level of $1.64 \mathrm{ng} / \mathrm{mL}$. Interestingly, in this study, after 45 days of recovery the testosterone level had only recovered to $2.2 \mathrm{ng} / \mathrm{mL}$ [22]. Although a different species of animal was used in these studies, our results tend to support the findings both in levels of testicular testosterone reported and in correlation to exposure to $\mathrm{HgCl}_{2}$.

4.3. Correlation of Testosterone and Latency to Impregnate. A unique finding in our study was the correlation between testicular testosterone levels and the latency to impregnate. As far as we are aware, this is the first time this particular comparison has been made. For testicular testosterone, within the control group the correlation coefficient was very high and significant; however, as the dose of $\mathrm{HgCl}_{2}$ increased the correlation became lower and lost its statistical significance. This is evident in the correlation of the low $\mathrm{Hg}$ group, which was lower than the controls and not significant, and the absence of any correlation in the high Hg group. Plasma testosterone levels, although having lower correlation coefficients' which were not significant, nevertheless, followed the same pattern as testicular testosterone results. This was confirmed by the high correlation between the two measures of testosterone and latency to impregnate indicating the results were very similar. This would suggest that while testosterone levels played an important factor in the time taken for the animals to mate in the control group, it became a less important factor as $\mathrm{HgCl}_{2}$ concentrations increased. This information presents two possibilities. Either $\mathrm{HgCl}_{2}$ reduces the amount of testosterone to the point that it no longer influences sexual activity, or the effect of $\mathrm{HgCl}_{2}$ exposure has a large enough effect on the mechanisms of reproduction, that is, a lowering of the sperm count, as to overcome repeated copulation. As is discussed later, it appears that morphological damage to spermatozoa is the greater factor affecting male reproduction, when mercury exposure has occurred, rather than a loss of libido.

4.4. Sperm Count of Epididymis Head and Body. A second factor contributing to the lower fertility and the increase of latency to impregnate was the lower sperm count in the epididymis head and body. Both exposed groups had significantly lower counts than the control group, (see Figure 6). Inspection of the distribution for the three groups indicates that there may be a dose-response effect, although it should be emphasized that there was no statistical difference between the two mercury-exposed groups. Exposure of mice to $1.25 \mathrm{mg} / \mathrm{kg}$ of $\mathrm{HgCl}_{2}$ by gavage for 45 days has been shown to significantly reduce the epididymis sperm count compared to controls while also reducing serum testosterone levels [22]. The same results were seen in another study administering the same dose for 30 days [9]. In both cases, the mating rate for the $\mathrm{HgCl}_{2}$ treated mice was zero [22]. A study on the reproductive effects of methylmercury in male rats showed a decrease in testicular sperm count of $27 \%$ after 14 days exposure, while also recording a decrease in testosterone levels after 6 days [23]. These results tend to concur with our study and support our findings.

The present study was designed to look at the effects of $\mathrm{HgCl}_{2}$ on fertility in growing male rats and not as a mechanistic analysis. However, close comparison with a recent report that does speculate on the mechanisms possibly responsible for the observed results is interesting.

Boujbiha, in his 2009 study, found very similar results to our study [21] including decreased testosterone, a decrease in mating index, and a lower viable implantation rate. We report a significantly longer period to impregnate control females by high exposure animals and a lower number of impregnations. Thus the data from the two studies tends to support each other even though there are significant methodological differences between the studies.

Studies of human populations into the effects of inorganic mercury on male fertility rates are very sparse. The majority of such studies focus on the mechanistic effects of mercury $[4,24,25]$; however, there is some evidence of reduced fertility in males due to mercury intoxication. More than one-third of male partners of infertile couples in Hong Kong had elevated blood mercury concentrations. As the authors of this study stated "From a public heath perspective, these findings confirm that mercury toxicity is a potentially serious problem affecting the local community," [7]. 
A study that looked at the environmental contaminant levels and fecundability on first pregnancies among nonsmoking couples reported that the partners of males who had blood $\mathrm{Hg}$ levels between $0.7-1.0$ and $1.9-4.8 \mu \mathrm{g} / \mathrm{L}$ had a greater time to pregnancy (TTP), 9.9 and 8.1 months, respectively, than a reference group with blood $\mathrm{Hg}$ levels of $0-0.6 \mu \mathrm{g} / \mathrm{L}$. Conversely, a group with levels of 1.1-1.8 $\mu \mathrm{g} / \mathrm{L}$ had a mean TTP of 5.1 months [26]. The authors stated "Reduced fecundability at levels below the mercury reference dose warrants further research and prudent reduction in persistent toxic substances exposure among women and men of reproductive age" [26].

The paucity of studies into the effects of male inorganic $\mathrm{Hg}$ exposure and the resultant effects on male reproduction in human populations, coupled with the results found in our and other recent research, would suggest that a larger more extensive study is required. Many of the studies that have been conducted have either had a small number of subjects [26], or the results are hard to analyze because of other conflicting variables [3]. Also, while some studies have reported the mechanistic results of human male exposure [7], the resultant effects on male reproduction in terms of fertility were not reported. Our study tended to use lower exposure concentrations than other recent studies [21], and found significant effects of $\mathrm{HgCl}_{2}$ exposure on male rat fertility.

The present study into the effects of $\mathrm{HgCl}_{2}$ on male reproduction in rats found there were significant effects including greater latency to impregnate a female, lower impregnation rates, loss of correlation between testosterone levels and time to impregnate, and lower sperm count in the epididymis head and body. These negative effects on male fertility were identified in the face of doses that were too low to be clinically toxic.

\section{Funding}

This publication was made possible by Grant no. RCMI 5 G12 RR003059 from the Research Centers in Minority Institutions (RCMI) at the National Institutes of Health and Grant no. 1R15ES020066-01 from the National Institutes of Health, National Institute of Environmental Health Sciences. Its contents are solely the responsibility of the authors and do not necessarily represent the official views of RCMI, NIH, or NIEHS.

\section{Acknowledgment}

The authors wish to express their sincere thanks and appreciation to Dr. Liz Simmons for her invaluable help in editing this paper.

\section{References}

[1] J. D. Meeker, M. G. Rossano, B. Protas et al., "Cadmium, lead, and other metals in relation to semen quality: human evidence for molybdenum as a male reproductive toxicant," Environmental Health Perspectives, vol. 116, no. 11, pp. 14731479, 2008.

[2] B. Baranski, "Effects of the workplace on fertility and related reproductive outcomes," Environmental Health Perspectives, vol. 101, no. 2, pp. 81-90, 1993.
[3] S. Tas, R. Lauwerys, and D. Lison, "Occupational hazards for the male reproductive system," Critical Reviews in Toxicology, vol. 26, no. 3, pp. 261-307, 1996.

[4] L. Barregard, G. Lindstedt, A. Schutz, and G. Sallsten, "Endocrine function in mercury exposed chloralkali workers," Occupational and Environmental Medicine, vol. 51, no. 8, pp. 536540, 1994.

[5] K. H. Alcser, K. A. Brix, L. J. Fine, L. R. Kallenbach, and R. A. Wolfe, "Occupational mercury exposure and male reproductive health," American Journal of Industrial Medicine, vol. 15, no. 5, pp. 517-529, 1989.

[6] C. M. Y. Choy, C. W. K. Lam, L. T. F. Cheung, C. M. BritonJones, L. P. Cheung, and C. J. Haines, "Infertility, blood mercury concentrations and dietary seafood consumption: a casecontrol study," International Journal of Obstetrics and Gynaecology, vol. 109, no. 10, pp. 1121-1125, 2002.

[7] T. Y. Leung, C. M. Y. Choy, S. F. Yim, C. W. K. Lam, and C. J. Haines, "Whole blood mercury concentrations in sub-fertile men in Hong Kong," Australian and New Zealand Journal of Obstetrics and Gynaecology, vol. 41, no. 1, pp. 75-77, 2001.

[8] H. I. Popescu, "Poisoning with alkylmercury compounds," British Medical Journal, vol. 1, no. 6123, p. 1347, 1978.

[9] A. K. Sharma, A. G. Kapadia, P. Fransis, and M. V. Rao, "Reversible effects of mercuric chloride on reproductive organs of the male mouse," Reproductive Toxicology, vol. 10, no. 2, pp. 153159, 1996.

[10] A. Atkinson, S. J. Thompson, A. T. Khan et al., "Assessment of a two-generation reproductive and fertility study of mercuric chloride in rats," Food and Chemical Toxicology, vol. 39, no. 1, pp. 73-84, 2001.

[11] T. K. Monsees, M. Franz, S. Gebhardt, U. Winterstein, W. B. Schill, and J. Hayatpour, "Sertoli cells as a target for reproductive hazards," Andrologia, vol. 32, no. 4-5, pp. 239-246, 2000.

[12] M. Arabi, "Bull spermatozoa under mercury stress," Reproduction in Domestic Animals, vol. 40, no. 5, pp. 454-459, 2005.

[13] M. Arabi and M. S. Heydarnejad, "In vitro mercury exposure on spermatozoa from normospermic individuals," Pakistan Journal of Biological Sciences, vol. 10, no. 15, pp. 2448-2453, 2007.

[14] M. V. Rao and B. Gangadharan, "Antioxidative potential of melatonin against mercury induced intoxication in spermatozoa in vitro," Toxicology In Vitro, vol. 22, no. 4, pp. 935-942, 2008.

[15] J. C. Heath, Y. Abdelmageed, T. D. Braden, A. C. Nichols, and D. A. Steffy, "The effects of chronic mercuric chloride ingestion in female Sprague-Dawley rats on fertility and reproduction," Food and Chemical Toxicology, vol. 47, no. 7, pp. 1600-1605, 2009.

[16] A. T. Khan et al., "Mercury levels in target organs of male rats following multiple doses of mercuric cholride," in Proceedings of the International Congress on the Health Effects of Hazardous Waste, Washington, DC, USA, 1995.

[17] A. T. Khan, T. C. Graham, J. E. Webster, D. M. Forester, and J. A. Ferguson, "Mercury levels in target organs of female rats following multiple doses of mercuric chloride," Toxicologist, vol. 335, p. 12, 1996.

[18] National Toxiclogy Program, Technical Report on the Toxicology and Carcinogenesis Studies of Mercuric Chloride in F344 Rats and B6C3F1 Mice, NIH, 1993.

[19] J. D. Park, S. S. M. Habeebu, and C. D. Klaassen, “Testicular toxicity of di-(2-ethylhexyl)phthalate in young SpragueDawley rats," Toxicology, vol. 171, no. 2-3, pp. 105-115, 2002.

[20] G. A. Wiggers, F. M. Peçanha, A. M. Briones et al., "Low mercury concentrations cause oxidative stress and endothelial 
dysfunction in conductance and resistance arteries," American Journal of Physiology, vol. 295, no. 3, pp. H1033-H1043, 2008.

[21] M. A. Boujbiha, K. Hamden, F. Guermazi et al., "Testicular toxicity in mercuric chloride treated rats: association with oxidative stress," Reproductive Toxicology, vol. 28, no. 1, pp. 8189, 2009.

[22] M. V. Rao and P. S. N. Sharma, "Protective effect of vitamin E against mercuric chloride reproductive toxicity in male mice," Reproductive Toxicology, vol. 15, no. 6, pp. 705-712, 2001.

[23] S. Homma-Takeda, Y. Kugenuma, T. Iwamuro, Y. Kumagai, and N. Shimojo, "Impairment of spermatogenesis in rats by methylmercury: involvement of stage- and cell- specific germ cell apoptosis," Toxicology, vol. 169, no. 1, pp. 25-35, 2001.

[24] D. G. Ellingsen, J. Efskind, E. Haug, Y. Thomassen, I. Martinsen, and P. I. Gaarder, "Effects of low mercury vapour exposure on the thyroid function in chloralkali workers," Journal of Applied Toxicology, vol. 20, no. 6, pp. 483-489, 2000.

[25] E. M. Erfurth, A. Schutz, A. Nilsson, L. Barregard, and S. Skerfving, "Normal pituitary hormone response to thyrotrophin and gonadotrophin releasing hormones in subjects exposed to elemental mercury vapour," British Journal of Industrial Medicine, vol. 47, no. 9, pp. 639-644, 1990.

[26] D. C. Cole, B. Wainman, L. H. Sanin, J. P. Weber, H. Muggah, and S. Ibrahim, "Environmental contaminant levels and fecundability among non-smoking couples," Reproductive Toxicology, vol. 22, no. 1, pp. 13-19, 2006. 

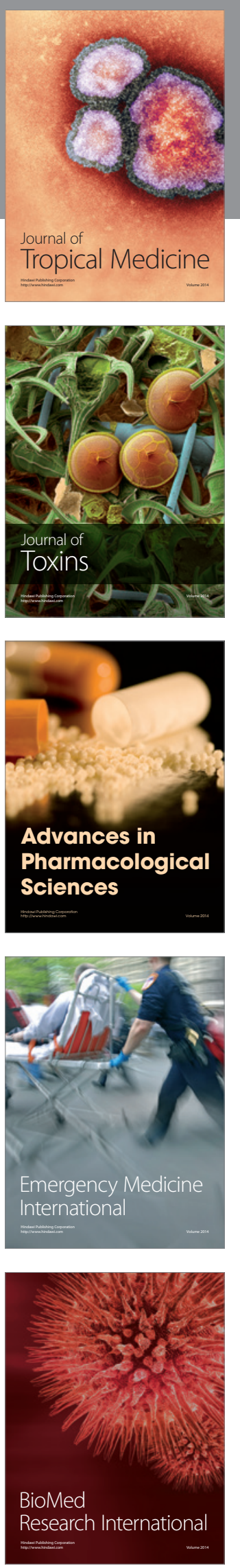
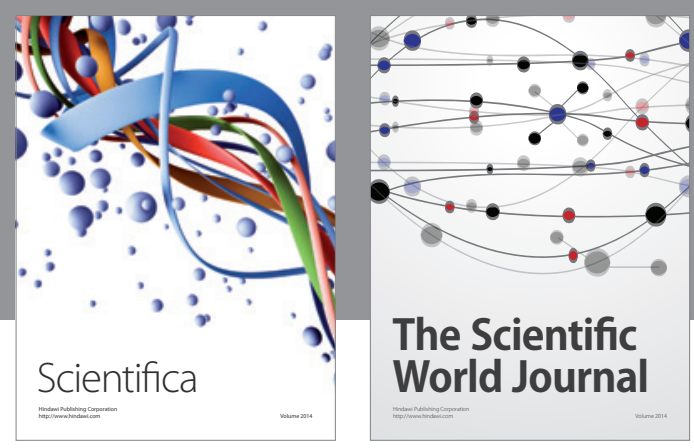

The Scientific World Journal
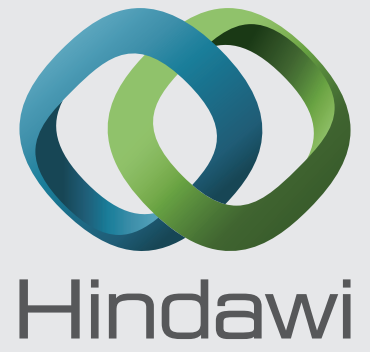

Submit your manuscripts at

http://www.hindawi.com
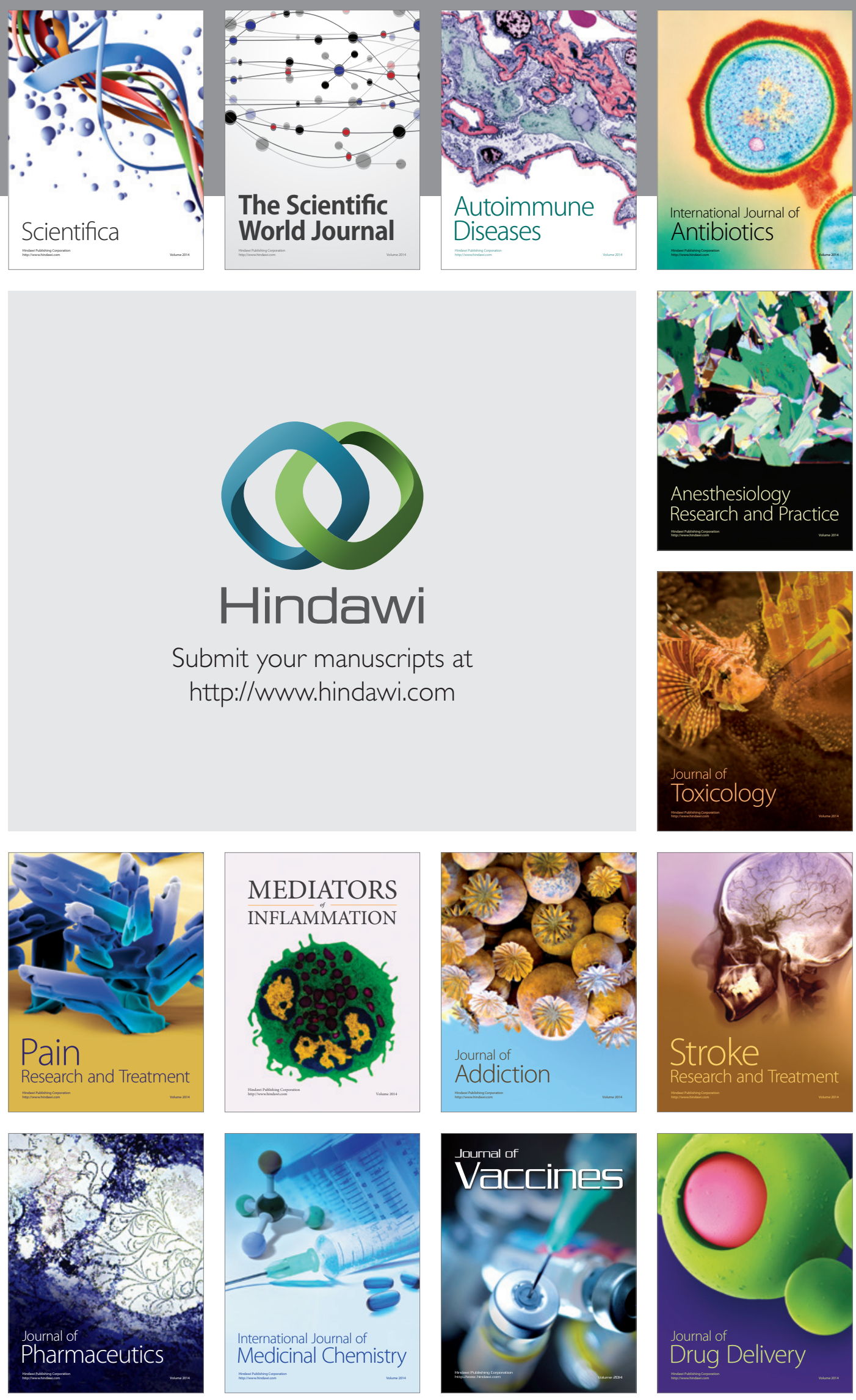